\title{
Intersectional analysis of Advanced Placement Physics participation and performance by gender and ethnicity
}

\author{
Robert Krakehlø \\ Institute for STEM Education, Stony Brook University, 092 Life Sciences, \\ Stony Brook, New York 11794-5233, USA \\ and Manhasset High School, 200 Memorial Place, Manhasset, New York 11030, USA \\ Angela M. Kelly॰* \\ Department of Physics \& Astronomy and Institute for STEM Education, Stony Brook University, \\ 092 Life Sciences, Stony Brook, New York 11794-5233, USA
}

(Received 2 April 2021; accepted 17 June 2021; published 29 July 2021)

\begin{abstract}
Access and performance in advanced high school physics have been persistently inequitable when considering student ethnicity and gender. This quasiexperimental, observational study examined access and performance of students in four Advanced Placement (AP) Physics courses in 2018-2019: AP Physics 1 $(N=150451)$, AP Physics $2(N=20466)$, AP Physics C Mechanics $(N=49951)$, and AP Physics $\mathrm{C}$ Electricity \& Magnetism $(N=21602)$; this analysis utilized an intersectional lens of ethnicity and gender in identifying enrollment and performance disparities. Descriptive and inferential analyses were conducted to determine whether the distribution of student ethnicities and genders of students who took the examinations was similar to that of U.S. schools. Further analyses were conducted to determine whether achievement on AP Physics examinations varied by 14 unique intersectional groups characterized by gender and ethnicity. Results indicated that AP Physics 1 was a relatively accessible course, though enrollment disparities among genders, ethnicities, and intersectional groups grew as the AP Physics courses became more advanced with physics and/or calculus prerequisites or corequisites. There were large decreases in course enrollments from first- to second-year AP Physics courses, particularly for women who were also underrepresented ethnic minorities. In terms of performance, AP Physics 1 had the lowest overall weighted average, with the majority of students failing the examination. Women who were traditionally underrepresented ethnic minorities were found to have failure rates of over $80 \%$ on the AP Physics 1 examination, and failure rates near 50\% for AP Physics 2 and the AP Physics C courses compared to nonminority men who had approximately half the failure rates. In most cases, men outperformed women who shared their ethnicities. These results present opportunities for physics education policy makers and researchers to design interventions for students in intersecting marginalized social groups, many of whom have disproportionately low representation and achievement in advanced high school physics, which occurs at a critical juncture in the physics pipeline.
\end{abstract}

DOI: 10.1103/PhysRevPhysEducRes.17.020105

\section{INTRODUCTION}

\section{A. Physics and equity in the precollege STEM pipeline}

Precollege physics coursetaking plays a vital role for students who wish to pursue postsecondary science, technology, engineering, and mathematics (STEM) study. Students who took a quantitative physics course in high

\footnotetext{
*angela.kelly@stonybrook.edu
}

Published by the American Physical Society under the terms of the Creative Commons Attribution 4.0 International license. Further distribution of this work must maintain attribution to the author(s) and the published article's title, journal citation, and DOI. school have demonstrated higher rates of STEM degree attainment in the U.S. [1-3]. Those who took a rigorous physics course also demonstrated higher STEM career interest [4,5]. While there has been an increase in high school physics course taking [6] and physics bachelor's degree attainment [7] in the U.S. in recent years, indicating an increase in physics persistence, there remains inequitable physics access and achievement when considering demographic factors such as ethnicity [8-13], gender [8], and socioeconomic status $[6,8,14,15]$.

\section{Intersectional perspectives}

While there has been a considerable amount of research related to equitable physics access and achievement for 
both ethnicity and gender, these two factors are often viewed in isolation from one another. STEM inclusion is a complex issue that requires broad perspectives and methodologies in contextualizing systemic disparities [16]. Malcolm et al.'s seminal work [17], The Double Bind: The Price of Being a Minority Woman in Science, was one of the first attempts to identify science exclusion in terms of both gender and ethnic minority status. The authors stressed the importance of intersectional data reporting that specifies both gender and ethnicity in all categories; this practice serves to highlight the educational position of minority women while identifying areas for potential intervention [17]. More recent physics education research incorporating the intersectionality of gender and ethnicity has demonstrated the insightful potential of this framework in improving performance, persistence, and diversity in physics [18-22]. However, there has been little research regarding intersectionality in precollege physics education, which constitutes a critical part of the STEM pipeline.

Addressing the STEM pipeline problem in the U.S. requires understanding of the educational gaps that may be widened throughout the academic continuum. Research has shown that $75 \%$ of female physics majors decided on their choice before and during high school, with $93 \%$ of female undergraduate degree holders taking physics during high school [23]. Despite recent research claiming gender parity in undergraduate physics performance in the U.S. [24], there remains evidence that physics persistence in terms of graduate study and careers remains a chronic issue [15]. While there has been an overall decrease in the gender achievement gap, with woman earning $57.3 \%$ of all science and engineer bachelor's degrees in 2017, they accounted for only $20.4 \%$ of bachelor's degrees in physics; this contrasts with related fields including chemistry and mathematics or statistics, which approximate parity in degree attainment [15]. Similarly, while there has been growth in previously identified underrepresented minority groups receiving bachelor's degrees in science and engineering fields, there still remain large achievement gaps. When compared to the distribution of ethnicities in the U.S., some groups such as Black, Hispanic, and American Indian students remain underrepresented in attaining bachelor's degrees in physics [15,25].

\section{Precollege physics access}

Similar disparities may be found within the K-12 education system in the U.S., which indicates this may be a hierarchical issue in the narrowing of the STEM pipeline [13]. The American Institute of Physics reported that parity was nearly achieved between men and women who enrolled in physics in 2009, although there were inequities when considering more advanced high school physics courses $[23,26]$. There has been growth in underrepresented minority students enrolling in physics [13], however, only $35 \%$ of the Black and $37 \%$ of the Hispanic student populations enrolled in physics in 2013 [15]. Black and Hispanic students were also shown to be at a positional disadvantage as they were often enrolled in "worse off" schools which offered fewer advanced physics courses compared to "better off" schools [10,13,14,27].

Historically, U.S. precollege physics has been the culminating science of either a three- or four-year high school sequence [28]. Even after the release of A Nation at Risk Report [29] calling for increased science and mathematics graduation requirements, physics has consistently had the lowest enrollments among the core sciences that also include biology and chemistry [15]. This is a particular issue for underrepresented students who have been identified as less likely to enroll in advanced mathematics and science courses [30,31]. Research has suggested that earlier placements in mathematics and science courses position students for later participation in advanced STEM courses $[32,33]$. However, accelerated learning has been shown to be inequitable based on sociocultural background [34], often leading to racial stratification in learning opportunities [35]. This has been the case in mathematics, which has led to negative influences on enrollment and achievement in advanced sciences [36,37]. In an effort to further explore equity issues of physics access and performance in precollege settings, the present study examines the intersectionality of ethnicity and gender in AP Physics access and performance.

\section{B. AP course taking and academic advantage}

The College Board's Advanced Placement Program was initiated in 1952 in an effort to expand access and uniformity in U.S. higher education. Advanced Placement courses are elective college-like courses that are offered in some secondary schools throughout the U.S. These courses culminate in a summative assessment that measures a student's ability in the course on a scale of one to five. A score of one implies that it is not recommended that a student receive credit for an equivalent course. A score of a five implies a student is extremely well qualified and has earned the equivalent of an $\mathrm{A}+$ or $\mathrm{A}$ in the respective college-level course. Equivalent courses are determined by the postsecondary school for which the student is attempting to receive credit [38]. This program has allowed advanced students to earn college credit to avoid course redundancy and to narrow the academic gap between secondary school and higher education $[39,40]$.

While there has been a large expansion of access to AP examinations in recent years, there has also been increased failure rates, with the number of students earning a score of one nearly doubling [41]. In some cases, AP programs continued to grow although few students earned a three or above on specific examinations [42]. Some schools push the notion of early college readiness, allowing for AP enrollment as early as 9 th and 10th grade although academic capabilities and preparation may be deficient [41]. 
This expansion has not been equitable when considering contextual factors such as socioeconomic status, ethnicity, and school size. Larger and densely populated schools tend to offer more AP courses, as opposed to smaller and high need schools $[40,43]$. Students traditionally underrepresented in STEM have been less likely to be enrolled compared to their counterparts, even when academically ready [44]. Klugman [35] suggested a supply and demand viewpoint for enrollment, indicating that while more underrepresented students may be recruited into AP courses, parity is difficult to achieve due to a greater demand for AP courses from affluent communities. Highly competitive colleges and universities consider AP experience a desirable credential [45], placing students who attend schools with limited AP access at a disadvantage. In terms of performance, research has indicated that Black, Hispanic, and low socioeconomic status students have passing rates of approximately one-third of the rates for White and higher income students [46]. Researchers have suggested equal access to AP courses should be paired with equitable preparation and support for all students $[47,48]$.

\section{AP STEM and academic advantage}

Research has documented several academic and positional advantages for students who enroll in AP science. Tai et al. [49] indicated that after controlling for prior academic achievement and early career expectations, students who took AP Calculus have been more likely to persist in physical science and engineering. Students who took an AP science other than environmental science were found to persist in life sciences as opposed to nonscience majors [49]. Dougherty et al. [50] found that students who took AP courses were often self-selecting and had characteristics that were linked to better college performance. AP participation may be an indicator of existing academic motivation as opposed to AP participation increasing academic motivation [51]. Students who enroll in an AP science courses typically have higher achievement in the same science in college, regardless of prior educational history and performance [52,53]. However, disparities persist in AP STEM performance. While overall AP STEM participation has grown, the failure rates have increased steadily from 1997 to 2010, more so for ethnic minorities than White and Asian students [54].

Participation in AP Physics has grown in recent years, and students who have taken the course experience certain advantages. Enrollment in AP or second year physics has grown from 25000 students in 1987, to 229000 students in 2013, and 241317 in 2019 [6,55]. A recent study indicated that in terms of introductory calculus-based physics performance, students who took AP Physics C performed well, and a score of five on the AP Physics 1 exam was also a predictor of strong performance. This suggests that both algebra- and calculus-based AP Physics courses are beneficial in terms of college physics performance [56]. More research is needed to understand student performance in terms of AP course variability [57], which is particularly appropriate in physics since there are four AP options.

\section{THEORETICAL FRAMEWORK}

The theoretical framework for the present study incorporates an intersectional perspective in examining equity in precollege advanced physics access and performance. Intersectionality is a theoretical paradigm that identifies ways in which structural discrimination may be embedded in academic domains [58]. Research has shown that ethnic and gender stereotypes are not additive- the intersectional hypothesis suggests perceptions of intersectional groups within social hierarchies are unique and distinct [59]. The examination of group differences in terms of the intersection of ethnicity and gender may surface STEM disparities that require remediation [60]. Such analyses may identify opportunities for meaningful reforms that promote the inclusion of women and traditionally underrepresented minorities in STEM disciplines. Institutional disaggregate data often provide a more complete understanding of how students with multiple identities experience the complexities of STEM learning environments [61].

Intersecting marginalized groups of students may share unique experiences and outcomes that affect STEM ability perceptions and persistence [62]. For example, women of color have often experienced both overt and subtle tensions and barriers in pursuing STEM post-secondary study and careers. Many STEM academic programs designed to serve women disproportionately advantage White women, while similar programs for underrepresented minority groups disproportionately favor men [63]; this concept has been characterized as double jeopardy due to the increased stigma of membership in two or more marginalized groups [64].

Researchers have identified physics as a particularly challenging space-women earned $21 \%$ of physics bachelor's degrees in 2016, yet just $4 \%$ were awarded to Black women and 7\% to Hispanic women [26]. Women of color have often struggled to assume legitimacy in physics due to experiences involving stereotype threat, perceived intellectual incompetence, microaggressions, and dissonance with the cultural practices of physics communities $[21,65,66]$. More work is needed to quantify structural inequities in educational settings that may contribute to the persistently low representation of women of color in mathematicsintensive fields [67].

This research examined intersectional access and performance to AP Physics in precollege settings. Since AP Physics is available in four different courses, two algebrabased and two calculus-based, this variability was explored through separate analyses for each course type. Differentiated access and performance by intersectional group may characterize contributing factors to hierarchical stereotypes and structural inequities in physics learning, 


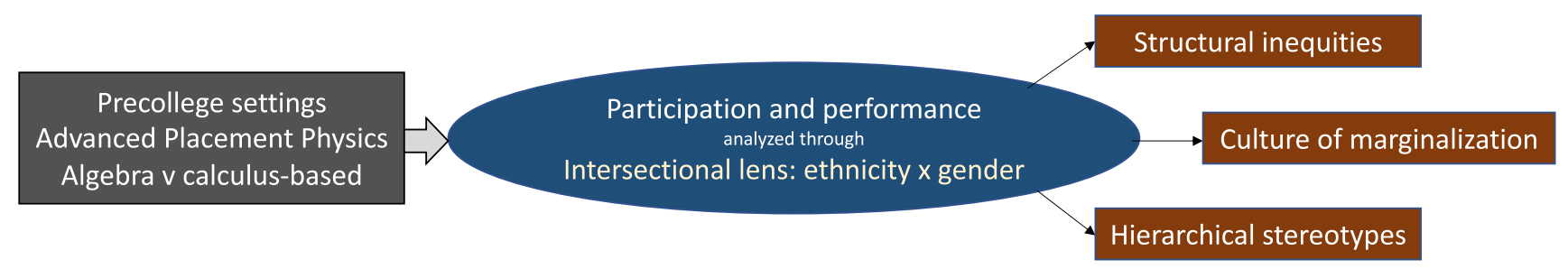

FIG. 1. Theoretical framework for intersectional analysis of Advanced Placement physics access and performance.

which perpetuate a culture of marginalization for students traditionally underrepresented in physics. The theoretical framework is represented in Fig. 1.

\section{A. Research questions}

The present study examined participation and performance in AP Physics through an intersectional framework. Most prior studies involving STEM intersectional inequities have been contextualized in undergraduate and graduate education (for example, Refs. [60,63,65-67]), however, the present study addresses an overt gap in the literature by applying intersectional analysis to precollege physics. The specificity of physics is highly relevant since participation and performance often predict majoring and persisting in STEM $[1,2,23]$. This research employed a two-pronged approach in analyzing College Board institutional data. The question of participation in advanced physics was explored in terms of ethnicity and gender individually, as well as intersectional group, and how these variables related to the overall public-school population in the U.S. The question of physics performance was examined solely through an intersectional lens, with weighted AP Physics averages on four examinations disaggregated by 14 intersectional groups characterized by both ethnicity and gender. Data included disaggregate figures on AP Physics test taking and scores from a large sample of students $(N=241347)$ in 2019 . The research questions included the following:

1. How does student participation in AP Physics courses vary by ethnicity and gender, as well as intersectional group? How does this compare to the ethnic, gender, and intersectional breakdown of precollege students in the U.S.?

2. To what extent do achievement gaps exist in the four AP Physics courses in terms of the intersectional identities of ethnicity and gender?

\section{DESIGN}

The quantitative research methods utilized in this study were part of a quasiexperimental observational design $[68,69]$. The design was cross sectional in that it utilized nonmanipulated disaggregated publicly available data for four different AP Physics examinations administered in 2019 in the U.S. The availability of these data presented a unique opportunity to analyze advanced physics performance with a well-known, standardized metric that has established validity recognized by many colleges and universities [38]. The accessibility of large-scale state and national datasets in recent years has resulted in an increase in quasiexperimental designs to provide transparent and rigorous policy evaluations [70]. This design was explanatory in that it utilized quantitative statistical analyses to identify the extent of equitable access and achievement on the four AP Physics examinations when considering the intersectionality of student ethnicity and gender [68]. The analysis incorporated both within-group examination of gender and ethnic categories when compared to the overall U.S. school population, and between-group intersectional analysis of physics access and performance; in doing so, relationships between membership in multiple social categories and structural inequalities might be identified [71].

\section{A. Context and intersectional groups}

In 2018, the National Center for Education Statistics reported the ethnic breakdown in U.S. public high schools (grades 9-12) as $47.4 \%$ White, $27.0 \%$ Hispanic, $15.4 \%$ Black, 5.2\% Asian, 3.6\% Multiracial, 1\% American Indian, and $0.4 \%$ Native Hawaiian [72]. It is approximated that the distribution of males and females in the United States public and private educational system are equal [73]. For the purposes of the present study, these percentages were used as a proxy of the overall U.S. student population as public-school students account for approximately $90 \%$ of the student population.

Data for this study were collected from the publicly released Advanced Placement score distributions for the 2019 AP Physics 1, AP Physics 2, AP Physics C Mechanics, and AP Physics C Electricity \& Magnetism examinations in the U.S. [55]. Data included test-taking enrollments and student scores disaggregated by gender and ethnicity. AP Physics 1 was the most widely taken physics examination $(n=150451)$, followed by AP Physics C Mechanics $(n=49951)$, AP Physics C Electricity \& Magnetism $(n=21602)$, and AP Physics $2(n=20466)$.

Intersectional groups were defined by ethnicity and gender. College Board [55] categorized students by seven specific ethnicities: American Indian, Asian, Black, Hispanic, Native Hawaiian, White, and Multiracial. The Asian category included students from the Indian subcontinent and the Philippines. Students who identified as 
Hispanic and another race were reported as Hispanic, and students reported as Multiracial were considered nonHispanic. These categories align with the National Center for Education Statistics guidelines of combining race and ethnicity in educational data reporting [72,74]. Race or ethnicity was a categorical variable with seven classifications. Gender was reported as a dichotomous variable (male or female). Consequently, there were 14 intersectional ethnicity and gender groups for each physics examination. These groups were not considered as additive in terms of gender and ethnicity, rather, they were identified and analyzed as unique, distinct entities, consistent with the intersectional hypothesis [59,62].

\section{B. AP Physics course content}

As of 2021, there were four AP Physics courses offered by the College Board. The curriculum for each AP Physics course and sample examination questions are publicly available from the College Board [75-78].

AP Physics 1 was designed to be a first-year algebrabased physics course, requiring no previous physics knowledge but recommending geometry as a prerequisite and algebra II as a corequisite [75]. According to College Board, AP Physics 1 is equivalent to a first-semester algebra-based college course with topics including kinematics; Newtonian mechanics; rotational kinematics and mechanics; and work, energy, and power.

AP Physics 2 was designed as a second-year algebrabased physics course, building on the topics of AP Physics 1 or a comparable course, with precalculus as a prerequisite or corequisite [76]. AP Physics 2 is equivalent to a second semester introductory college physics course covering topics such as fluid mechanics; thermodynamics; electricity and magnetism; and atomic and nuclear physics.

The AP Physics C courses are both calculus-based physics courses that are recommended as second-year courses in high school. Some schools offer AP Physics $\mathrm{C}$ Mechanics as an intensive first year course although it is not recommended by the College Board [77,78]. Calculus is a recommended prerequisite or corequisite. Topics covered in AP C Mechanics include kinematics; Newton's laws of motion; work, energy, and power; systems of particles and linear momentum; rotation; and oscillations and gravitation [78]. AP C Electricity \& Magnetism includes topics such as electrostatics; conductors, capacitors, and dielectrics; electric circuits; magnetic fields; and electromagnetism [77].

For all the AP Physics courses, the College Board recommends a minimum of $25 \%$ of course time dedicated to experimentation, equivalent to that of a college laboratory [75-78]. Notably, there is considerable overlap between AP Physics 1 and AP Physics C Mechanics, as well as AP Physics 2 and AP Physics C Electricity \& Magnetism, although there are topics in AP Physics 2 not covered in AP Physics $\mathrm{C}$ such as fluid mechanics, thermodynamics, optics, and modern physics.

\section{Data analysis}

Data analytical methods for this study included descriptive statistics, chi-square goodness-of-fit tests, and nonparametric comparisons of means. Descriptive statistics were generated using publicly available datasets that reported nationwide intersectional enrollment and achievement on AP Physics 1, AP Physics 2, AP Physics C Mechanics, and AP Physics C Electricity \& Magnetism examinations in 2019. These statistics included enrollment by intersectional groups, and the number within each group who achieved scores from one through five. The passing score on the AP examinations is generally a three, although this varies in terms of scores needed to earn credit at specific colleges [38]. A score of a three was considered passing for the purposes of this study. From the scores, a weighted average was calculated based upon the percentages of each group in each scoring category.

The following null hypotheses were tested to answer the corresponding research questions:

Research Question 1: How does student participation in AP Physics courses vary by ethnicity and gender, as well as intersectional group? How does this compare to the ethnic, gender, and intersectional breakdown of precollege students in the U.S.?

1. $\mathrm{H}_{0}$ : The representation of each ethnic group who took the AP Physics examinations was not different than the percentage of each ethnic group enrolled in U.S. schools.

2. $\mathrm{H}_{0}$ : The representation of each gender group who took the AP Physics examinations was not different than the percentage of each gender group enrolled in U.S. schools.

3. $\mathrm{H}_{0}$ : The representation of each intersectional group who took the AP Physics examinations was not different than the percentage of each intersectional group enrolled in U.S. schools.

Research Question 2: To what extent do achievement gaps exist in the four AP Physics courses in terms of the intersectional identities of ethnicity and gender?

4. $\mathrm{H}_{0}$ : Physics performance will not vary by intersectional groups defined by ethnicity and gender.

5. $\mathrm{H}_{0}$ : Physics performance will not vary when comparing men and women within each ethnic group.

To test the first, second, and third hypotheses, chi-square goodness-of-fit tests were conducted to determine whether there were significant differences between the distribution of gender, ethnicities, and intersectional groups for students who took each AP Physics examination and the students enrolled in U.S. public schools. For the fourth and fifth hypotheses, Welch's analysis of variance (ANOVA) with Games-Howell post hoc tests were conducted to determine whether there were significant differences in physics 
achievement in terms of intersectional groups of ethnicity and gender. American Indian and Native Hawaiian intersectional groups were not included in the performance analyses since there enrollments were less than $0.15 \%$ of the population for each test. In some cases, as few as four students from one of these groups took an exam which may have compromised their anonymity. The post hoc tests revealed whether there were significant differences between men and women within each ethnic group. ANOVA results were analyzed in conjunction with descriptive statistics to identify performance disparities in intersectional groups.

Assumptions of normality were checked by Q-Q plots. Because of the size of the samples tested, it was assumed that the skewed distributions could be modeled by normal distributions due to the central limit theorem [79]. Homogeneity of variance between groups could not be assumed for each of the ANOVA tests, as determined by Levene's test ( $p<0.001)$, consequently, Welch's ANOVA and Games-Howell post hoc tests were used.

\section{RESULTS}

\section{A. AP Physics enrollment}

\section{AP Physics 1 access}

A chi-square test indicated that the observed ethnic distribution for students taking the AP Physics 1 examination was significantly different than the expected distributions when compared to public schools in the U.S., $\chi^{2}(6)=54.43, p<0.001$. Descriptive data are summarized in Table I. Asian students accounted for a larger portion of students than expected. Hispanic, Black, American Indian, and Native Hawaiian students accounted for a lower percentage than expected. Additionally, a second chi-square test indicated that the expected equal distribution of men and women did not match the observed values, with men accounting for $60.4 \%$ of the sample, $\chi^{2}(1)=4.37, p=0.036$. The distribution of intersectional groups was significantly different than expected when compared to the distribution in public schools in the U.S., $\chi^{2}(13)=61.40, p<0.001$. The participation of all female groups was lower than their male counterparts, with the exception of Black students. White men enrolled at a higher rate than expected, and White women enrolled at a lower rate.

\section{AP Physics 2 access}

Similarly, a chi-square analysis was performed to compare observed ethnic distributions for students taking the AP Physics 2 examination. The model was significant, $\chi^{2}(6)=89.78, p<0.001$. Black, Hispanic, American Indian, and Native Hawaiian students accounted for a lower percentage than expected, whereas Asian students accounted for a larger portion than expected. The distribution of men and women in AP Physics 2 was significantly different than expected, $\chi^{2}(1)=18.88, p<0.001$. Men accounted for $71.7 \%$ of the students taking the AP Physics 2 examination. The distribution of intersectional groups was significantly different than expected when compared to the public schools in the U.S., $\chi^{2}(13)=122.23, p<0.001$. The participation of all female groups was lower than their male counterparts. As with AP Physics 1, White men enrolled at a higher rate, and White women enrolled at a lower rate.

TABLE I. AP Physics enrollment percentages by intersectional group as compared to U.S. secondary enrollment in grades 9-12, 2018 $[55,72]$.

U.S. secondary

Intersectional group $^{\mathrm{a}}$ population (\%) AP Physics $1(\%)$ AP Physics $2(\%)$ AP Physics C Mechanics (\%) AP Physics C E/M (\%)

\begin{tabular}{|c|c|c|c|c|c|}
\hline Amer Indian female & 0.5 & 0.085 & 0.034 & 0.038 & 0.023 \\
\hline Amer Indian male & 0.5 & 0.14 & 0.13 & 0.10 & 0.083 \\
\hline Asian female & 2.6 & 8.2 & 7.6 & 9.3 & 9.5 \\
\hline Asian male & 2.6 & 12.1 & 16.9 & 20.9 & 26.4 \\
\hline Black female & 7.7 & 2.4 & 1.1 & 0.84 & 0.54 \\
\hline Black male & 7.7 & 2.4 & 1.8 & 1.6 & 1.4 \\
\hline Hispanic female & 13.5 & 8.2 & 4.0 & 2.8 & 2.0 \\
\hline Hispanic male & 13.5 & 11.5 & 10.3 & 7.3 & 6.6 \\
\hline Multiracial female & 1.8 & 2.0 & 1.4 & 1.5 & 1.2 \\
\hline Multiracial male & 1.8 & 2.8 & 3.4 & 3.4 & 3.5 \\
\hline Nat Hawaiian female & 0.2 & 0.051 & 0.020 & 0.026 & 0.037 \\
\hline Nat Hawaiian male & 0.2 & 0.092 & 0.083 & 0.046 & 0.046 \\
\hline White female & 23.7 & 18.6 & 14.1 & 13.7 & 10.8 \\
\hline White male & 23.7 & 31.4 & 39.1 & 38.5 & 37.7 \\
\hline
\end{tabular}

${ }^{a}$ Ethnic group percentages were divided in two to estimate intersectional group percentages, since the National Center for Education Statistics and many states do not report secondary enrollments by gender. 


\section{AP Physics C Mechanics access}

The chi square model examining AP Physics C Mechanics access was significant, $\chi^{2}(6)=143.64$, $p<0.001$, indicating variance in distributions by ethnicity. Black, Hispanic, American Indian, and Native Hawaiian students accounted for lower percentages of the student population than expected, while Asian students accounted for a larger portion than expected. The distribution of men and women in AP Physics C Mechanics was significantly higher than expected, $\chi^{2}(1)=19.05, p<0.001$. Men accounted for $71.9 \%$ of the students taking AP Physics $\mathrm{C}$ Mechanics. The distribution of intersectional groups was significantly different than expected when compared to the public schools in the U.S., $\chi^{2}(13)=184.29, p<0.001$. Similar trends for both AP Physics 1 and 2 were found with a larger percentage of White men than expected, and White women enrolling at a lower rate than expected. In all cases, the participation of all female groups was lower than their male counterparts.

\section{AP Physics C Electricity \& Magnetism access}

The chi square model measuring ethnic participation AP Physics C Electricity \& Magnetism was significant $\chi^{2}(6)=206.96, p<0.001$, indicating variance in distributions. Black, Hispanic, American Indian, and Native Hawaiian students accounted for lower portions of the student population than expected, whereas Asian students accounted for a larger portion than expected. The distribution of men in AP Physics C Electricity \& Magnetism was significantly higher than expected, $\chi^{2}(1)=26.66$, $p<0.001$. Men accounted for $75.8 \%$ of the AP Physics Electricity \& Magnetism students. The distribution of intersectional groups was significantly different than expected when compared to public schools in the U.S., $\chi^{2}(13)=279.46, p<0.001$. A larger percentage of White men than expected, and White women enrolling at a lower rate than expected. The participation of all female groups was lower than their male counterparts.

\section{AP Physics access summary}

For all AP physics examinations, Asian women tended to be overrepresented compared to all other intersectional groups that included women, except for Multiracial women in the AP Physics 1 course. Asian, White, and Multiracial men were found to be overrepresented in each of the AP Physics courses, whereas Black, Hispanic, American Indian, and Native Hawaiian men tended to be underrepresented. The percentage of men in each examination was higher than their women counterparts, except for Black men and women in AP Physics 1.

Enrollment and performance data for all AP Physics examinations are summarized in Table I.

\section{B. Performance in AP Physics 1 and 2}

\section{Intersectional analysis of AP Physics 1 performance}

When examining differences among intersectional group AP Physics 1 scores, a one-way ANOVA with the GamesHowell post hoc test indicated that there were significant differences in the weighted mean scores, Welch's $F(9,24908.82)=3163.62, p<0.001$, Cohen's $d=0.77$, a medium to large effect. Since so few American Indian and Native Hawaiian scores were reported, intersectional groups with these ethnicities were not included in subsequent analyses. For all remaining ethnic groups, men had a higher weighted average than women $(p<0.001)$. This is consistent with research that suggests gender is often a stronger predictor of academic outcomes related to STEM career pathways than ethnicity [80].

Notable findings were further identified by descriptive statistics for all intersectional groups, as represented in Table II. More than half of students who took the AP Physics 1 examination (56.1\%) scored below a score of three, with an overall weighted average score of $\bar{x}=2.46$. This is consistent with research suggesting expanded access to AP course taking often results in lower passing rates $[41,42]$.

When considering intersectional groups, Asian men and White men performed the highest on the AP Physics 1 examination, with average scores of $\bar{x}=2.98$ and $\bar{x}=2.78$, respectively; however, a significant number of these intersectional groups still failed the examination (38.7\% of Asian men and $44.9 \%$ of White men). These groups outperformed their female ethnic counterparts $(p<0.001)$, with Asian women experiencing a failure rate of $49.7 \%$, and White women a failure rate of $59.2 \%$.

The failure rates for women who were also underrepresented ethnic minorities was exceedingly high. These groups included Hispanic women (86.4\%) and Black women (87.7\%), who were also outperformed by their male ethnic counterparts $(p<0.001)$. The failure rates for men from traditionally underrepresented ethnic groups in STEM were: Hispanic men $(72.7 \%)$ and Black men $(76.8 \%)$.

Multiracial men outperformed Multiracial women $(p<0.001)$, and their respective performances were on the borderline between the dominant and underrepresented ethnicities. Multiracial men had a failure rate of $46.3 \%$, and Multiracial women $60.5 \%$.

\section{Intersectional analysis of AP Physics 2 performance}

AP Physics 2 scores were also analyzed for differences among intersectional groups. A one-way ANOVA with the Games-Howell post hoc test indicated that there were significant differences among the weighted mean scores, Welch's $F(9,2278.63)=203.36, p<0.001, d=0.59$, a medium to large effect. When looking at gender differences 
TABLE II. Score distributions in AP Physics 1 and 2, disaggregated by intersectional group and the number and percentage of students in each group earning scores 1 through 5 [55].

\begin{tabular}{|c|c|c|c|c|c|c|c|}
\hline & & $n(\%)$ & $n(\%)$ & $n(\%)$ & $n(\%)$ & $n(\%)$ & \\
\hline Group $^{\mathrm{a}}$ & $N$ & Score $1 / 5^{b}$ & Score $2 / 5$ & Score $3 / 5$ & Score $4 / 5$ & Score $5 / 5$ & Weighted avg score \\
\hline \multicolumn{8}{|l|}{ AP PHYSICS 1} \\
\hline Total students & 150451 & $40283(26.8)$ & $44090(29.3)$ & $30920(20.6)$ & $26365(17.5)$ & $8793(5.8)$ & 2.46 \\
\hline \multicolumn{8}{|c|}{ Intersectional groups (Ethnicity and gender) } \\
\hline Asian male & 18254 & $2724(14.9)$ & $4341(23.8)$ & $4127(22.6)$ & $4631(25.4)$ & $2431(13.3)$ & 2.98 \\
\hline White male & 47268 & $7188(15.2)$ & $14048(29.7)$ & $11541(24.4)$ & $10805(22.9)$ & $3686(7.8)$ & 2.78 \\
\hline Multiracial male & 4141 & 749 (18.1) & 1168 (28.2) & 904 (21.8) & $920(22.2)$ & $400(9.7)$ & 2.77 \\
\hline Asian female & 12302 & $2430(19.8)$ & 3680 (29.9) & $2876(23.4)$ & $2570(20.9)$ & $746(6.1)$ & 2.64 \\
\hline White female & 28035 & $6646(23.7)$ & $9957(35.5)$ & $6434(22.9)$ & $4207(15.0)$ & $791(2.8)$ & 2.38 \\
\hline Multiracial female & 2969 & 785 (26.4) & $1011(34.1)$ & $616(20.7)$ & $444(15.0)$ & $113(3.8)$ & 2.36 \\
\hline Hispanic male & 17320 & $7730(44.6)$ & $4872(28.1)$ & $2481(14.3)$ & $1773(10.2)$ & $464(2.7)$ & 1.98 \\
\hline Black male & 3615 & $1734(48.0)$ & $1042(28.8)$ & $482(13.3)$ & $303(8.4)$ & $54(1.5)$ & 1.87 \\
\hline Hispanic female & 12387 & $7812(63.1)$ & $2890(23.3)$ & $1069(8.6)$ & $535(4.3)$ & $81(0.7)$ & 1.56 \\
\hline Black female & 3610 & $2263(62.7)$ & $902(25.0)$ & $309(8.6)$ & $124(3.4)$ & $12(0.3)$ & 1.54 \\
\hline \multicolumn{8}{|l|}{ AP PHYSICS 2} \\
\hline Total students & 20466 & $1862(9.1)$ & 5737 (28.0) & $6316(30.9)$ & 4050 (19.8) & $2501(12.2)$ & 2.98 \\
\hline \multicolumn{8}{|c|}{ Intersectional groups (Ethnicity and gender) } \\
\hline Asian male & 3460 & $168(4.9)$ & $691(20.0)$ & $982(28.4)$ & $849(24.5)$ & $770(22.3)$ & 3.39 \\
\hline Multiracial male & 695 & $54(7.8)$ & $54(7.8)$ & $212(30.5)$ & $150(21.6)$ & $115(16.5)$ & 3.16 \\
\hline Asian female & 1564 & $112(7.2)$ & $396(25.3)$ & $488(31.2)$ & $349(22.3)$ & $219(14.0)$ & 3.11 \\
\hline White male & 7993 & $432(5.4)$ & $2136(26.7)$ & $2702(33.8)$ & $1739(21.8)$ & $984(12.3)$ & 3.09 \\
\hline Multiracial female & 285 & $25(8.8)$ & $75(26.3)$ & $104(36.5)$ & $49(17.2)$ & $32(11.2)$ & 2.96 \\
\hline White female & 2894 & $265(9.2)$ & $926(32.0)$ & $970(33.5)$ & $537(18.6)$ & $196(6.8)$ & 2.82 \\
\hline Hispanic male & 2116 & $425(20.1)$ & $750(35.4)$ & $544(25.7)$ & $256(12.1)$ & $141(6.7)$ & 2.50 \\
\hline Black male & 361 & $70(19.4)$ & $153(42.4)$ & $94(26.0)$ & $32(8.9)$ & $12(3.3)$ & 2.34 \\
\hline Black female & 217 & $61(28.1)$ & $85(39.2)$ & $50(23.0)$ & $19(8.8)$ & $2(0.9)$ & 2.15 \\
\hline Hispanic female & 826 & $241(29.2)$ & $337(40.8)$ & $156(18.9)$ & $67(8.1)$ & $25(3.0)$ & 2.15 \\
\hline
\end{tabular}

${ }^{\mathrm{a}}$ Scores of American Indian and Native Hawaiian students are not reported here due to small sample size $(<0.15 \%$ of the test takers for each AP Physics examination), however, they are still included in the aggregate totals.

${ }^{\mathrm{b}}$ Number of students earning scores reported on a scale of 1 through 5 , with a score of 3 considered passing.

within individual ethnic groups, significant differences were only found for Asian men $(\bar{x}=3.39)$ and women $(\bar{x}=3.11)(p<0.001)$; Hispanic men $(\bar{x}=2.50)$ and women $(\bar{x}=2.15) \quad(p<0.001) ;$ and White men $(\bar{x}=3.09)$ and women $(\bar{x}=2.82)(p<0.001)$. There were fewer gender disparities within ethnic groups for AP Physics 2 than AP Physics 1.

The weighted average for all AP Physics 2 students was $\bar{x}=2.98$, with the majority of students earning a score of three or greater $(62.9 \%)$. Although the scores were higher than AP Physics 1, there were still notable inequities. When considering intersectional categories, both men and women in ethnic groups traditionally underrepresented in STEM were found to experience failure rates of greater than $50 \%$. These groups included Hispanic men (55.5\%), Black men (61.8\%), Black women (67.3\%), and Hispanic women $(70.0 \%)$.

It is notable that Asian female students were among the highest achieving groups, with higher achievement than all groups except for Multiracial men and Asian men.

\section{Performance in AP Physics C \\ 1. Intersectional analysis of AP Physics $C$ Mechanics performance}

When examining AP Physics C Mechanics performance, a one-way ANOVA with the Games-Howell post hoc test indicated that there were significant differences among the weighted mean scores among the subgroups, Welch's $F(8,4889.18)=333.08, p<0.001, d=0.51$, a medium effect.

Descriptive statistics revealed that nearly twice as many students took AP Physics C Mechanics $(N=49951)$ compared to AP Physics C Electricity \& Magnetism $(N=21602)$ and AP Physics $2(N=20449)$, however, enrollment in AP Physics C Mechanics was only one-third of the number of students enrolled in AP Physics 1.

The overall weighted average for students who took AP Physics C Mechanics was $\bar{x}=3.72$, with the majority of students earning a three or higher $(81.2 \%)$, and $36.1 \%$ of students earning the highest score of five. Descriptive statistics revealed that women from ethnic groups traditionally underrepresented in STEM underachieved 
TABLE III. Score distributions in AP Physics $C$ Mechanics and Electricity \& Magnetism, disaggregated by intersectional group and the number and percentage of students in each group earning scores 1 through 5 [55].

\begin{tabular}{|c|c|c|c|c|c|c|c|}
\hline Group $^{\mathrm{a}}$ & $N$ & $\begin{array}{c}n(\%) \\
\text { Score } 1 / 5^{\mathrm{b}}\end{array}$ & $\begin{array}{c}n(\%) \\
\text { Score } 2 / 5\end{array}$ & $\begin{array}{c}n(\%) \\
\text { Score } 3 / 5\end{array}$ & $\begin{array}{c}n(\%) \\
\text { Score } 4 / 5\end{array}$ & $\begin{array}{c}n(\%) \\
\text { Score } 5 / 5\end{array}$ & Weighted avg score \\
\hline \multicolumn{8}{|c|}{ AP PHYSICS C-MECHANICS } \\
\hline Total students & 49951 & $4160(8.3)$ & $5212(10.4)$ & 8957 (17.9) & $13582(27.2)$ & $18040(36.1)$ & 3.72 \\
\hline \multicolumn{8}{|c|}{ Intersectional groups (Ethnicity and gender) } \\
\hline Asian male & 10450 & $545(5.2)$ & $738(7.1)$ & $1434(13.7)$ & $2678(25.6)$ & $5055(48.4)$ & 4.05 \\
\hline Multiracial male & 1705 & $101(5.9)$ & $161(9.4)$ & $280(16.4)$ & $455(26.7)$ & $708(41.5)$ & 3.88 \\
\hline White male & 19253 & $1225(6.4)$ & $1737(9.0)$ & $3363(17.5)$ & $5553(28.8)$ & $7375(38.3)$ & 3.84 \\
\hline Asian female & 4623 & $299(6.5)$ & $446(9.6)$ & $868(18.8)$ & $1317(28.5)$ & $1693(36.6)$ & 3.79 \\
\hline Multiracial female & 752 & $67(8.9)$ & $104(13.8)$ & $173(23.0)$ & $202(26.9)$ & $206(27.4)$ & 3.50 \\
\hline White female & 6850 & $690(10.1)$ & $959(14.0)$ & 1487 (21.7) & $1950(28.5)$ & $1764(25.8)$ & 3.46 \\
\hline Hispanic male & 3639 & $598(16.4)$ & 531 (14.6) & $753(20.7)$ & $886(24.3)$ & 871 (23.9) & 3.25 \\
\hline Black male & 775 & $142(18.3)$ & $140(18.1)$ & $168(21.7)$ & $181(23.4)$ & 144 (18.6) & 3.06 \\
\hline Hispanic female & 1376 & $336(24.4)$ & $298(21.7)$ & $309(22.5)$ & $261(19.0)$ & $172(12.5)$ & 2.73 \\
\hline Black female & 421 & $132(31.4)$ & $81(19.2)$ & $98(23.3)$ & $74(17.6)$ & $36(8.6)$ & 2.53 \\
\hline \multicolumn{8}{|c|}{ AP PHYSICS C-ELECTRICITY \& MAGNETISM } \\
\hline Total students & 21602 & $2311(10.7)$ & $3767(17.4)$ & $2893(13.4)$ & $4989(23.1)$ & $7642(35.4)$ & 3.55 \\
\hline \multicolumn{8}{|c|}{ Intersectional groups (Ethnicity and gender) } \\
\hline Asian male & 5707 & $456(8.0)$ & $783(13.7)$ & $660(11.6)$ & $1219(21.4)$ & $2589(45.4)$ & 3.82 \\
\hline Multiracial male & 764 & $59(7.7)$ & $115(15.1)$ & $109(14.3)$ & $190(24.9)$ & $291(38.1)$ & 3.71 \\
\hline Asian female & 2054 & $177(8.6)$ & $358(17.4)$ & $269(13.1)$ & $511(24.9)$ & $739(36.0)$ & 3.62 \\
\hline White male & 8148 & $778(9.5)$ & $1406(17.3)$ & 1107 (13.6) & $1907(23.4)$ & $2950(36.2)$ & 3.59 \\
\hline Multiracial female & 267 & $25(9.4)$ & $62(23.2)$ & $45(16.9)$ & $65(24.3)$ & $70(26.2)$ & 3.35 \\
\hline White female & 2341 & $280(12.0)$ & $523(22.3)$ & $370(15.8)$ & $612(26.1)$ & $556(23.8)$ & 3.27 \\
\hline Hispanic male & 1423 & $276(19.4)$ & 275 (19.3) & $213(15.0)$ & $328(23.0)$ & $331(23.3)$ & 3.11 \\
\hline Black male & 299 & $81(27.1)$ & $72(24.1)$ & $39(13.0)$ & $55(18.4)$ & $52(17.4)$ & 2.75 \\
\hline Hispanic female & 442 & $112(25.3)$ & $135(30.5)$ & $67(15.2)$ & $76(17.2)$ & $52(11.8)$ & 2.60 \\
\hline Black female & 116 & $54(46.6)$ & $25(21.6)$ & $11(9.5)$ & $19(16.4)$ & $7(6.0)$ & 2.14 \\
\hline
\end{tabular}

${ }^{\text {a }}$ Scores of American Indian and Native Hawaiian students are not reported here due to small sample size $(<0.15 \%$ of the test takers for each AP Physics examination), however, they are still included in the aggregate totals.

${ }^{\mathrm{b}}$ Number of students earning scores reported on a scale of 1 through 5 , with a score of 3 considered passing.

compared to other intersectional groups. Black women were found to be at a particular disadvantage with $50.6 \%$ of test takers failing the examination. For all other intersectional groups, more than half the students passed the AP Physics $\mathrm{C}$ Mechanics examination, although the lowest scores $(\bar{x}<3.00)$ were earned by Hispanic women $(\bar{x}=2.73)$, and Black women $(\bar{x}=2.53)$. Significant differences were found in the mean weighted averages between men and women within each ethnicity (Table III).

\section{Intersectional analysis of AP Physics $C$ Electricity \& Magnetism performance}

With regard to AP Physics C Electricity \& Magnetism performance, a one-way ANOVA with the Games-Howell post hoc test indicated that there were significant differences between the weighted mean score among the subgroups, Welch's $F(9,1615.90)=103.73, p<0.001$, $d=0.42$, a small to medium effect.

The overall weighted average for students who took the AP Physics C Electricity \& Magnetism exam was $\bar{x}=3.55$, with the majority of students earning a score of three or better $(71.9 \%)$, and $35.4 \%$ of students earning a five. Similar to the other AP physics examinations, significant differences were found between the genders within each ethnicity.

When considering intersectional groups, results were similar to those of AP Physics C Mechanics. Asian men $(\bar{x}=3.82)$, Multiracial men $(\bar{x}=3.71)$, Asian women $(\bar{x}=3.62)$, and White men $(\bar{x}=3.59)$ were the highest achievers. The lowest scores $(\bar{x}=3.00)$ were earned by Black men $(\bar{x}=2.75)$, Hispanic women $(\bar{x}=2.60)$, and Black women $(\bar{x}=2.14)$. Failure rates of greater than $50 \%$ were experienced by Black men (51.2\%), Hispanic women (55.8\%), and Black women (68.2\%).

\section{DISCUSSION}

\section{A. Conclusions}

The results of the present study highlight considerable demographic disparities in enrollment and performance in AP Physics. Precollege physics is an important context since many women and underrepresented ethnic groups do not persist in physics in post-secondary study; indeed, this time period has been identified as the "one significant leak 
in the physics pipeline" since many young women take physics in high school yet they earn few of bachelor's degrees in physics [81] (p. 13). Although intersectionality has been proposed as an insightful analytical lens for exploring inequities in STEM participation and performance $[21,60,61,67]$, this perspective has rarely been applied in physics education research, particularly at the high school level. The results of this study are discussed in terms of AP access and performance, and intersectional group disparities. This is followed by implications for practice, study limitations, and suggestions for future lines of inquiry.

\section{AP Physics access and performance}

The four AP Physics courses were differentiated in terms of enrollment and performance. Enrollment in algebrabased AP Physics 1 was over 150000 in 2019, which was approximately three times the enrollment in AP Physics C Mechanics, and seven times the enrollment in AP Physics 2 and AP Physics C Electricity \& Magnetism. The relatively high student participation in AP Physics 1 may be explained by the nature of the course-it was designed to be taken as a first-year course, and it requires a lower level of mathematical preparation and proficiency than the AP Physics C courses. AP Physics 1 is typically a prerequisite for AP Physics 2. Notably, the high enrollment in AP Physics 1 may be positioning students at a long-term disadvantage with regard to STEM persistence, since the overall weighted mean score was $\bar{x}=2.46$, and more than half of students in all but four of the intersectional groups failed the examination. Exceptionally high failure rates were reported for underrepresented women, with $88 \%$ of Black women and $86 \%$ of Hispanic women failing. Women from ethnic groups traditionally underrepresented in STEM have been previously identified as having to reconcile multiple identities with their cultural misalignment with physics communities in order to develop a sense of belonging in the field $[21,65,66]$. With so many of students in traditionally marginalized groups experiencing failure, it raises the question as to how well schools are serving these students at a critical juncture in the STEM pipeline.

The high enrollment and low performance in AP Physics 1 is consistent with studies that suggested such courses reach a point of saturation, where too many unprepared students are enrolling and not meeting AP academic standards [41,42]. Research has indicated that schools may be incentivized to enroll students in as many AP courses as possible for accreditation and accountability [82], while many students who took AP Physics did not report their scores to their colleges [56,83]. Although studies have demonstrated that physics course taking is correlated to persistence and post-secondary success in STEM [1-3], student achievement in these courses was not directly addressed, which may have perpetuated a misleading narrative that exposure is equivalent to learning the material. The coinciding of high enrollments with high failure rates necessitates the examination of persistence as more than just course taking - supports for learning and performance must be implemented for expanded access to advanced physics to be effective.

Students in second-year AP Physics courses all demonstrated higher passing rates [AP Physics $2(\bar{x}=2.98)$, AP Physics C Mechanics $(\bar{x}=3.72)$, AP Physics C Electricity \& Magnetism $(\bar{x}=3.55)]$ and lower failure rates when compared to AP Physics 1 [AP Physics 2 (27.1\%), AP Physics C Mechanics (18.8\%), AP Physics C Electricity \& Magnetism (28.1\%)]. However, intersectional analyses indicated inequitably higher failure rates for students traditionally underrepresented in physics, particularly Black and Hispanic women. The higher scores may have been due to the prerequisites of the courses, including passing AP Physics 1, and the expected mathematical precursors and proficiencies. Since many students failed AP Physics 1, fewer students may have been allowed to enroll in second-year physics courses. This is also supported by the notion that students enrolling in second-year courses may be self-selecting motivated students who already possess positional academic advantages tied to persistence in STEM [50,51].

\section{Intersectional group disparities}

As the selectivity and rigor increased among the AP Physics courses (in terms of recommended prerequisities and mathematical presentation), the enrollment distribution of student ethnicities increasingly diverged from the U.S. school population. As indicated in prior research related to AP participation, Black, Hispanic, American Indian, and Native Hawaiian students were all underrepresented in AP Physics courses [84]. Since AP Physics 2 and AP Physics C courses were recommended as second-year courses, the inequitable decreases in enrollment may be partly explained by disparities in access based on students' socioeconomic and sociocultural backgrounds $[10,13,14,27,34,35]$. Furthermore, research has shown that high poverty schools that serve a majority of students underrepresented in STEM tend to have restricted access to advanced science and mathematics courses such as AP Physics [10,14,30,31,35,85]. Failure rates in AP Physics 1 may also provide a plausible explanation, which is further supported by the lack of students reporting AP Physics scores $[56,83]$. The negative reputation associated with the likelihood of failure may discourage students from taking AP Physics courses due to undesirable academic repercussions and diminished post-secondary options.

For nearly all AP Physics courses, men tended to outscore women in most ethnicities. Black and Hispanic women tended to be among the lowest scoring groups on all AP Physics examinations. This exemplifies the "double jeopardy" consequence for women traditionally underrepresented in physics, where they experience cumulative 
disadvantages by virtue of their membership in multiple underrepresented groups $[64,86]$. Membership in socially marginalized groups may disproportionately influence students' experiences and feelings of belonging in physics $[21,65,66]$. More research is needed to understand how these experiences might deter high school students, particularly women of color, from persisting in STEM due to negative experiences with academic failure and the cultural practices of physics classrooms.

\section{B. Implications}

\section{Broadening access and diminished performance}

While high school physics access has been a persistent issue [6,8-15], it is important for schools and policy makers to consider the idea of oversaturation [41,42]. Algebrabased AP Physics provided the widest access likely due to lower-level mathematical prerequisites and corequisities, yet the failure rates were extremely high, suggesting underlying problems related to prior academic preparation. Also, increased selectivity and mathematical rigor in AP Physics $\mathrm{C}$ increased the gender gap in participation yet decreased the achievement gap, as evidenced by effect sizes. While research has suggested there is increased achievement with when access is restricted [14], these conditions may be confounded by student self-selection based on perceived relevance and interest $[87,88]$ and prerequisite science and mathematics course taking [89]. With increased access to AP coursework there needs to be an equivalent increase in student academic preparation and support $[47,48]$, particularly for academically marginalized intersectional groups.

Findings may also indicate misalignment between what is taught in the course and what is measured on the examination [83]. Curricular fidelity to College Board standards has often been cited as an issue in select schools [90,91]. While the College Board states prerequisite recommendations in their examination descriptions [75-78], the audit process does not appear to take into consideration whether students had access to the academic prerequisites. Additionally, some students may be at a disadvantage as the courses have material based on physics experimentation, which may be inequitable depending on available school resources [31,89]. These issues require further exploration to determine whether contextual structural inequalities impact ethnic minority women disproportionately.

Traditionally in the U.S., students take physics in either 11th or 12th grade and often follow a four-year science sequence which may inhibit the taking of a second year of physics [28,92]. Research has shown that many of the students who were identified as underrepresented in this study's findings have been shown to have lower enrollments in prerequisite and corequisite courses $[11,15,30]$. The science course sequence and availability of advanced mathematics are issues for consideration in designing interventions to promote physics accessibility and learning.

\section{Physics failure and sociocognitive impacts}

It is important to consider some of the psychosocial phenomena that often result from a lack of academic success. The prevalence of failure in high enrollment advanced STEM courses such as AP Physics 1 may influence the task self-efficacy beliefs, physics selfconcept, and outcomes expectations of many students, particularly those underrepresented in the field. More than $80 \%$ of women of color failed this examination and did not receive college credit for the course. This is an alarming rate of failure that may impact the intentions of these women to pursue STEM careers that involve postsecondary physics coursetaking. One such sociocognitive impact is diminished self-efficacy, which is the belief that one can accomplish specific tasks to reach a certain goal [93], in this case, understanding and applying the physics principles in the curriculum. Self-efficacy has been shown to be a significant predictor of physics achievement and persistence [94-96]. If these women do not believe they can master an introductory physics course, they may not formulate career aspirations that depend upon this task. Self-efficacy and career outcomes expectations have been identified as significant predictors of the STEM career intentions of intersectional groups [60].

Physics related self-concept, or sense of belonging in the field, is often formed by comparing one's academic performance to that of one's peers, and evaluating personal physics academic success when compared to other school subjects [97]; this has also been shown as a significant predictor of physics achievement and career interest [98]. Students who do not formulate a sense of belonging based on failure in AP Physics may further exacerbate the lack of diversity in physics post-secondary study and careers. Students who are traditionally underrepresented in STEM, specifically, women of color, may be particularly vulnerable to the effects of failure. Poor performance may reinforce stereotype threat, or the confirmation of negative racial and gender stereotypes about their capacity to excel in physics [99]. These stereotypes may also influence instructors' perceptions and latent biases about physics performance [100]; this is consequential since teacher encouragement has been shown to foster physics identity [101,102]. Physics educators should consider ways in which traditionally marginalized high school students might be better supported in advanced physics coursework. Potential interventions include critical feedback [103], instructors communicating beliefs about effort and malleable intelligence [104], and fostering social inclusion in physics communities of practice [65].

\section{Limitations}

There were several limitations to this study. The data collected and released by the College Board were detailed, yet certain categorizations were missing [55]. Although intersectionality data were disaggregated in terms of 
ethnicity and gender, other relevant identities were not considered, for example, socioeconomic status, physical or cognitive disability, and sexual orientation. Both socioeconomic status and location have been shown to be predictors of physics achievement [14], therefore, the inclusion of other social categorizations would provide additional transparency. Intersectional data provide context for students' experiences in shared academic pursuits, which identifies areas for targeted interventions. Since the data were aggregated across the U.S., many of the contextual details could not be studied. Although the use of national data may increase generalizability, the nature of education policy localized. Data disaggregated by locale and school needsto-resource capacity would highlight poverty-related disparities.

Some students enrolled in AP Physics did not take the exam, and some who took the exam did not report their scores [83]. Consequently, select students enrolled in AP Physics in 2019 were not included as part of the sample. This may have introduced selection bias with lower performing students not included in the analysis. Since students had to pay to take the examinations, it is possible that students took the course but could not afford the testing fee, which may have eliminated students in high poverty schools from the sample.

The College Board recommends course credit if students earn a score of a three of greater [38]. While this metric has often been used in research [57], it is not generalizable since not all colleges accept a score of a three as credit, if they accept the AP score at all. Some colleges require scores of a four or a five [38]. Utilizing three as a cutoff point may mask further inequities that are related to persistence, since students may be unwilling to repeat similar coursework in college.

The study also has some limited internal validity related to the research design. Many variables contributed to student performance outcomes aside from correlating membership in gender, ethnic, and intersectional groups. These include students' sociocognitive perspectives, school conditions and resources, teacher characteristics and qualifications, and fidelity to the AP Physics curricula. The authors acknowledge that the intersectional analysis had inherent limitations related to the limited predictive scope of the independent variables. Future research might examine contextual conditions that more clearly characterize observed disparities.

\section{Future research}

This study has raised several questions that may be examined in future studies to elicit insights for broadening access and improving performance in secondary physics. As physics education is largely contextual and localized, large scale hierarchical studies could examine additional school-, teacher-, and student-level variables that may predict, mediate, and/or moderate access and performance. Such independent variables may include the availability of science or mathematics prerequisities, tracking, socioeconomic status, teacher certification and experience, student STEM interest, and prior academic performance. Qualitative research on the formulation and persistence of STEM career aspirations in relation to AP Physics performance may be conducted to examine factors that inform targeted interventions. In both quantitative and qualitative work, an intersectional lens provides a means to evaluate group discrimination based upon marginalized social identities; these studies may provide powerful, insightful paradigms for deconstructing structural inequalities [71]. This work is essential in STEM communities where women of color are persistently underrepresented [17,60,61,67].

With AP Physics 1 being reasonably accessible but demonstrating significant achievement gaps among intersectional groups, interventions that target high risk students in AP Physics 1 may be explored in order to improve the quality of learning occurring in the classrooms. Researchers should examine ways in which supports and scaffolds may be implemented to improve overall performance and diminish achievement gaps for traditionally marginalized students. With many students only taking a first-year course that is predominantly mechanics based, qualitative studies regarding student beliefs on the relevance of physics topics are warranted. This may foster more culturally relevant learning environments that better support students [105].

The present study provides a unique examination of how enrollment and performance in AP Physics is differentiated among intersectional groups, as well as singular groups defined by ethnicity and gender. The identification of these disparities in high school physics presents opportunities for policy makers and researchers to explore this issue in greater depth. In pursuing this line of inquiry in future work, more equitable practices and outcomes may be identified to avoid chronic physics pipeline constraints at the juncture of high school and higher education.

\section{ACKNOWLEDGMENTS}

The authors would like to thank Martin Palermo, Keith Sheppard, Eric Mazur, Thomas Weinacht, and the anonymous reviewers for their insightful recommendations for this manuscript. 
[1] W. Tyson, R. Lee, K. M. Borman, and M. A. Hanson, Science, technology, engineering, and mathematics (STEM) pathways: High school science and math coursework and postsecondary degree attainment, J. Educ. Students Placed at Risk 12, 243 (2007).

[2] W. Tyson, Modeling engineering degree attainment using high school and college physics and calculus coursetaking and achievement, J. Eng. Educ. 100, 760 (2011).

[3] X. Wang, Why students choose STEM majors: Motivation, high school learning, and postsecondary context of support, Am. Educ. Res. J. 50, 1081 (2013).

[4] ACT, Developing the STEM Education Pipeline (ACT, Washington, DC, 2006).

[5] P. M. Sadler, G. Sonnert, Z. Hazari, and R. Tai, The role of advanced high school coursework in increasing stem career interest, Sci. Educat. 23, 1 (2014), https://eric.ed .gov/?id=EJ1034751.

[6] S. White and C. L. Tesfaye, High School Physics Courses and Enrollments: Results from the 2012-13 Nationwide Survey of High School Physics Teachers, https://www .aip.org/statistics/reports/high-school-physics-coursesenrollments-0, 2014

[7] P. J. Mulvey and S. Nicholson, Physics Bachelor's Degrees: 2018. Results from the 2018 Survey of Enrollments and Degrees, https://www.aip.org/statistics/reports/ physics-bachelors-degrees-2018, 2020.

[8] A. L. Griffith, Persistence of women and minorities in STEM field majors: Is it the school that matters?, Econ. Educ. Rev. 29, 911 (2010).

[9] A. M. Kelly and K. Sheppard, Newton in the Big Apple: Access to high school physics in New York City, Phys. Teach. 46, 280 (2008).

[10] A. M. Kelly and K. Sheppard, Secondary physics availability in an urban setting: Issues related to academic achievement and course offerings, Am. J. Phys. 77, 902 (2009).

[11] U. S. Department of Education, Office of civil rights, in STEM Course Taking (U. S. Department of Education, Washington, DC, 2018).

[12] S. White and J. Tyler, Who Teaches High School Physics? Results from the 2012-13 Nationwide Survey of High School Physics Teachers, https://www.aip.org/statistics/ reports/who-teaches-high-school-physics-0, 2014.

[13] S. White and J. Tyler, Underrepresented Minorities in High School Physics: Results from the 2012-13 Nationwide Survey of High School Physics Teachers, https://www.aip .org/statistics/reports/underrepresented-minorities-highschool-physics, 2015.

[14] R. Krakehl, A. M. Kelly, K. Sheppard, and M. Palermo, Physics teacher isolation, contextual characteristics, and student achievement, Phys. Rev. Phys. Educ. Res. 16, 020117 (2020).

[15] National Science Board, Science and Engineering Indicators 2018 (National Science Foundation, Alexandria, VA, 2018).

[16] H. Metcalf, D. Russell, and C. Hill, Broadening the science of broadening participation in STEM through critical mixed methodologies and intersectionality frameworks, Am. Behav. Sci. 62, 580 (2018).
[17] S. M. Malcom, P. Q. Hall, and J. W. Brown, The Double Bind: The Price of Being a Minority Woman in Science (American Association for the Advancement of Science, Report of a Conference of Minority Women Scientists, Arlie House, Warrenton, VA, 1976).

[18] E. Hennessey, J. Cole, P. Shastri, J. Esquivel, C. Singh, R. Johnson, and S. Ghose, Workshop report: Intersecting identities-gender and intersectionality in physics, AIP Conf. Proc. 2109, 040001 (2019).

[19] L. T. Ko, R. R. Kachchaf, M. Ong, and A. K. Hodari, Narratives of the double bind: Intersectionality in life stories of women of color in physics, astrophysics and astronomy, AIP Conf. Proc. 1513, 222 (2013).

[20] J. M. Nissen, I. H. M. Horses, and B. Van Dusen, Investigating society's educational debts due to racism and sexism in student attitudes about physics using quantitative critical race theory. Phys. Rev. Phys. Educ. Res. 17, 010116 (2021).

[21] A. L. Traxler, X. C. Cid, J. Blue, and R. Barthelemy, Enriching gender in physics education research: A binary past and a complex future, Phys. Rev. Phys. Educ. Res. 12, 020114 (2016).

[22] B. Van Dusen and J. Nissen, Equity in college physics student learning: A critical quantitative intersectionality investigation, J. Res. Sci. Teach. 57, 33 (2020).

[23] S. White and C. L. Tesfaye, Female Students in High School Physics: Results from the 2008-09 Nationwide Survey of High School Physics Teachers (American Institute of Physics, College Park, MD, 2011), https://www.aip.org/ statistics/reports/female-students-high-school-physics

[24] M. Dew, J. Perry, L. Ford, W. Bassichis, and T. Erukhimova, Gendered performance differences in introductory physics: A study from a large land-grant university, Phys. Rev. Phys. Educ. Res. 17, 010106 (2021).

[25] U. S. Census Bureau, QuickFacts United States (U. S. Department of Commerce, Washington, DC, 2019), https:// www.census.gov/quickfacts/fact/table/US/PST045219.

[26] A. M. Porter and R. Ivie, Women in Physics and Astronomy, 2019, https://www.aip.org/statistics/reports/ women-physics-and-astronomy-2019?dm_i=21LG, 682YQ,EMUFG9,OIV4Y,1, 2019.

[27] A. M. Kelly and K. Sheppard, Access to elite urban science schools in the U.S.: Opportunity, disparate impact, and equal protection, Teachers College Record (2019), https:// www.tcrecord.org/Content.asp?ContentID=22951.

[28] K. Sheppard and D. M. Robbins, Physics was once first and was once for all, Phys. Teach. 41, 420 (2003).

[29] National Commission on Excellence in Education, $A$ Nation at Risk: The Imperative for Educational Reform (U.S. Department of Education, Washington, DC, 1983).

[30] National Action Council for Minorities in Engineering, Inc., Pre-College Challenges for URMs in Engineering (National Action Council for Minorities in Engineering, Inc., White Plains, NY, 2014).

[31] W. F. Tate, B. D. Jones, E. Thorne-Wallington, and M. C. Hogrebe, Science and the city: Thinking geospatially about opportunity to learn, Urban Educ. 47, 399 (2012).

[32] F. G. Paul, Grouping within Algebra I: A structural sieve with powerful effects for low-income, minority, and 
immigrant students, Educ. Eval. Policy Anal. 19, 262 (2005).

[33] F. R. Spielhagen, Closing the achievement gap in math: The long-term effects of eighth-grade algebra, J. Adv. Academics 18, 34 (2006).

[34] H. Ayalon and A. Gamoran, Stratification in academic secondary programs and educational inequality in Israel and the United States, Comparative Educ. 44, 54 (2000).

[35] J. Klugman, The Advanced Placement arms race and the reproduction of educational inequality, Teachers College Record 115, 1 (2013), https://www.tcrecord.org/Content .asp?ContentId $=16965$.

[36] X. Ma, Understanding the relationship between mathematics, and science coursework patterns, Teachers College Record 111, 2101 (2009), https://www.tcrecord.org/ Content.asp?ContentId $=15382$.

[37] C. Muller, C. Riegle-Crumb, K. S. Schiller, L. Wilkinson, and K. Frank, Race and academic achievement in racially diverse high schools: Opportunity and stratification, Teachers College Record 112, 1038 (2010), https:// www.ncbi.nlm.nih.gov/pmc/articles/PMC2893342/.

[38] College Board, AP Credit Policy Search (College Board, New York, NY, 2021).

[39] K. Klopfenstein and M. K. Thomas, The link between Advanced Placement experience and early college success, South. Econ. J. 75, 873 (2009), https://www .semanticscholar.org/paper/The-Link-between-AdvancedPlacement-Experience-and-Klopfenstein-Thomas/ 5d97cdec475fe0c410a08970dc2394d938e0f720.

[40] R. T. Warne, R. Larsen, B. Anderson, and A. J. Odasso, The impact of participation in the Advanced Placement program on students' college admissions test scores, J. Educ. Res. 108, 400 (2015).

[41] E. Judson and A. Hobson, Growth and achievement trends of Advanced Placement (AP) exams in American high schools, Am. Secondary Educ. 43, 59 (2015), https:// www.jstor.org/stable/43694211.

[42] W. Lichten, in AP: A Critical Examination of the Advanced Placement Program, edited by P. M. Sadler, G. Sonnert, R. H. Tai, and K. Klopfenstein (Harvard Education Press, Cambridge, MA, 2010), pp. 233-243.

[43] P. Handwerk, N. Tognatta, R. J. Coley, and D. H. Gitomer, Access to Success: Patterns of Advanced Placement Participation in U.S. High Schools, Policy Information Report (Educational Testing Service, Princeton, NJ, 2008).

[44] College Board, The 9th Annual AP Report to the Nation (College Board, New York, NY, 2013).

[45] C. O. Sathre and C. D. Blanco, Moving the Needle on Access and Success: A Study of State and Institutional Policies and Practices (Western Interstate Commission for Higher Education, Boulder, CO, 2006).

[46] National Center for Educational Achievement, The Advanced Placement Program Benefits Mainly WellPrepared Students Who Pass AP Exams (ACT, Inc., Iowa City, IA, 2010).

[47] C. M. Callahan, Advanced Placement and International Baccalaureate Programs for Talented Students in American High Schools: A Focus on Science and Mathematics
(National Research Center on the Gifted and Talented, Storrs, CT, 2003).

[48] R. M. Kyburg, H. Hertberg-Davis, and C. M. Callahan, Advanced Placement and International Baccalaureate Programs: Optimal learning environments for talented minorities?, J. Adv. Academics 18, 172 (2007).

[49] R. H. Tai, C. Q. Liu, J. T. Almarode, and X. Fan, in AP: A Critical Examination of the Advanced Placement Program, edited by P. M. Sadler, G. Sonnert, R. H. Tai, and K. Klopfenstein (Harvard Education Press, Cambridge, MA, 2010), pp. 109-119.

[50] C. Dougherty, L. Mellor, and S. Jian, The Relationship between Advanced Placement and College Graduation. 2005 AP Study Series, Report 1 (National Center for Educational Achievement, Austin, TX, 2006).

[51] R. R. Bryan, S. M. Glynn, and J. Kittleson, Motivation, achievement, and Advanced Placement intent of high school students learning science, Sci. Educ. 95, 1049 (2011).

[52] P. M. Sadler and G. Sonnert, in AP: A Critical Examination of the Advanced Placement Program, edited by P. M. Sadler, G. Sonnert, R. H. Tai, and K. Klopfenstein (Harvard Education Press, Cambridge, MA, 2010), pp. 119-137.

[53] P. M. Sadler and R. H. Tai, Advanced Placement exam scores as a predictor of performance in introductory college biology, chemistry and physics courses, Sci. Educat. 16, 1 (2007), https://files.eric.ed.gov/fulltext/ EJ783418.pdf.

[54] E. Judson, Science and mathematics Advanced Placement exams: Growth and achievement over time, J. Educ. Res. 110, 209 (2017).

[55] College Board, AP Participation and Performance Data 2019 (College Board, New York, NY, 2019).

[56] E. W. Burkholder, AP physics: A closer look, Phys. Rev. Phys. Educ. Res. 17, 013101 (2021).

[57] R. T. Warne, Research on the academic benefits of the Advanced Placement program: Taking stock and looking forward, SAGE Open 7, 1 (2017).

[58] S. Cho, K. W. Crenshaw, and L. McCall, Toward a field of intersectionality studies: Theory, applications, and praxis, Signs: J. Women Culture Soc. 38, 785 (2013).

[59] N. Ghavami and L. A. Peplau, An intersectional analysis of gender and ethnic stereotypes: Testing three hypotheses, Psychol. Women Q. 37, 113 (2013).

[60] A. Byars-Winston and J. G. Rogers, Testing intersectionality of race/ethnicity $\times$ gender in a social-cognitive career theory model with science identity, J. Counsel. Psychol. 66, 30 (2019).

[61] J. Gaston Gayles and K. N. Smith, Advancing theoretical frameworks for intersectional research on women in STEM, New Dir. Institutional Res. 2018, 27 (2018).

[62] D. T. Ireland, K. E. Freeman, C. E. Winston-Proctor, K. D. DeLaine, S. McDonald Lowe, and K. M. Woodson, (Un) hidden figures: A synthesis of research examining the intersectional experiences of Black women and girls in STEM education, Rev. Res. Educ. 42, 226 (2018).

[63] M. Ong, C. Wright, L. Espinosa, and G. Orfield, Inside the double bind: A synthesis of empirical research on 
undergraduate and graduate women of color in science, technology, engineering, and mathematics, Harv. Educ. Rev. 81, 172 (2011).

[64] J. C. Williams, Double jeopardy? An empirical study with implications for the debates over implicit bias and intersectionality, Harvard J. Law Gender 37, 185 (2014), https:// repository.uchastings.edu/faculty_scholarship/1278.

[65] M. Ong, Body projects of young women of color in physics: Intersections of gender, race, and science, Soc. Probl. 52, 593 (2005).

[66] M. Ong, J. M. Smith, and L. T. Ko, Counterspaces for women of color in STEM higher education: Marginal and central spaces for persistence and success, J. Res. Sci. Teach. 55, 206 (2018).

[67] L. Malcom and S. M. Malcom, The double bind: The next generation, Harv. Educ. Rev. 81, 162 (2011).

[68] B. Johnson, Toward a new classification of nonexperimental quantitative research, Educ. Res. 30, 3 (2001).

[69] W. R. Shadish, T. D. Cook, and D. T. Campbell, Experimental and Quasi-Experimental Designs for Generalized Causal Inference (Houghton Mifflin, Boston, MA, 2002).

[70] M. Gopalan, K. Rosinger, and J. B. Ahn, Use of quasiexperimental research designs in education research: Growth, promises, and challenges, Rev. Res. Educ. 44, 218 (2020).

[71] N. M. Else-Quest and J. S. Hyde, Intersectionality in quantitative psychological research: II. Methods and techniques, Psychol. Women Q. 40, 319 (2016).

[72] National Center for Education Statistics, Enrollment in Public Elementary and Secondary Schools by Level, Grade, and Race/Ethnicity 2018, https://nces.ed.gov/ programs/digest/d20/tables/dt20_203.65.asp?current=yes.

[73] K. Bauman and S. Cranney, School Enrollment in the United States: 2018, Population Characteristics, Current Population Reports P20-584 (U.S. Census Bureau, Washington, DC, 2020).

[74] National Center for Education Statistics, Status and Trends in the Education of Racial and Ethnic Groups 2016 (U.S. Department of Education, Washington, DC, 2016).

[75] College Board, AP Physics 1 Course and Exam Description (College Board, New York, NY, 2019).

[76] College Board, AP Physics 2 Course and Exam Description (College Board, New York, NY, 2019).

[77] College Board, AP Physics C: Electricity and Magnetism Course and Exam Description (College Board, New York, NY, 2019).

[78] College Board, AP Physics C: Mechanics Course and Exam Description (College Board, New York, NY, 2019).

[79] R. G. Miller, Beyond ANOVA: Basics of Applied Statistics (CRC Press, Boca Raton, FL, 1997).

[80] S. Nix and L. Perez-Felkner, Difficulty orientations, gender, and race/ethnicity: an intersectional analysis of pathways to STEM degrees, Soc. Sci. 8, 43 (2019).

[81] R. Ivie and K. N. Ray, Women in physics and astronomy, 2005, https://www.aip.org/sites/default/files/statistics/ women/women-pa-05.pdf, 2005.

[82] Education Commission of the States, Adavanced Placement: State Provides Accountability Incentives for AP
Courses (Education Commission of the States, Denver, CO, 2021).

[83] E. W. Burkholder and C. E. Wieman, What do AP physics courses teach and the AP physics exam measure?, Phys. Rev. Phys. Educ. Res. 15, 020117 (2019).

[84] J. P. Gollub and R. Spital, Advanced physics in the high schools, Phys. Today 55, No. 5, 47 (2002).

[85] S. White and C. L. Tesfaye, High School Physics Availability: Results from the 2012-13 Nationwide Survey of High School Physics Teachers, https://www.aip.org/ statistics/reports/high-school-physics-availability-0, 2014.

[86] S. Yang, B. A. Jackson, and A. Zajicek, A changing landscape? An intersectional analysis of race and gender disparity in access to social capital, Sociol. Spectrum 41, 80 (2021).

[87] C. Williams, M. Stanisstreet, K. Spall, E. Boyes, and D. Dickson, Why aren't secondary students interested in physics?, Phys. Educ. 38, 324 (2005).

[88] F. McDonnell, Why so few choose physics: An alternative explanation for the leaky pipeline, Am. J. Phys. 73, 583 (2005).

[89] A. M. Kelly, Physics teachers' perspectives in factors that affect urban physics participation and accessibility, Phys. Rev. Phys. Educ. Res. 9, 010122 (2013).

[90] S. J. Cech, Number of schools offering AP falls after first audit of courses, Educ. Week 27, 1 (2007), https:// www.edweek.org/teaching-learning/number-of-schoolsoffering-ap-falls-after-first-audit-of-courses/2007/11.

[91] R. W. Schwenz and S. Miller, The AP Chemistry course audit: A fertile ground for identifying and addressing misconceptions about the course and process, J. Chem. Educ. 91, 1362 (2014).

[92] K. Sheppard and D. M. Robbins, Chemistry, the central science? The history of the high school science sequence, J. Chem. Educ. 82, 561 (2005).

[93] G. Hardy, Academic self-concept: Modeling and measuring for science, Res. Sci. Educ. 44, 549 (2014).

[94] A. M. Cavallo, W. H. Potter, and M. Rozman, Gender differences in learning constructs, shifts in learning constructs, and their relationship to course achievement in a structured inquiry, yearlong college physics course for life science majors, School Sci. Math. 104, 288 (2004).

[95] V. Sawtelle, E. Brewe, and L. H. Kramer, Exploring the relationship between self-efficacy and retention in introductory physics, J. Res. Sci. Teach. 49, 1096 (2012).

[96] G. Nehmeh and A. M. Kelly, Facilitating the self-determination of undergraduate women in physics: The role of external validation, Res. Sci. Technol. Educ. (2020).

[97] J. Möller and H. W. Marsh, Dimensional comparison theory, Psychol. Rev. 120, 544 (2013).

[98] B. Nagengast and H. W. Marsh, Big fish in little ponds aspire more: Mediation and cross-cultural generalizability of school-average ability effects on self-concept and career aspirations in science, J. Educ. Psychol. 104, 1033 (2012).

[99] G. C. Marchand and G. Taasoobshirazi, Stereotype threat and women's performance in physics, Int. J. Sci. Educ. 35, 3050 (2013). 
[100] S. I. Hofer, Studying gender bias in physics grading: The role of teaching experience and country, Int. J. Sci. Educ. 37, 2879 (2015).

[101] Z. Hazari, G. Sonnert, P. M. Sadler, and M.-C. Shanahan, Connecting high school physics experiences, outcome expectations, physics identity, and physics career choice: A gender study, J. Res. Sci. Teach. 47, 978 (2010).

[102] G. Nehmeh and A. M. Kelly, Women physicists and sociocognitive considerations in career choice and persistence, J. Women Minorities Sci. Engr. 24, 95 (2018).
[103] D. S. Yeager, V. Purdie-Vaughns, J. Garcia, N. Apfel, P. Brzustoski, A. Master, W. T. Hessert, M. E. Williams, and G. L. Cohen, Breaking the cycle of mistrust: Wise interventions to provide critical feedback across the racial divide, J. Exp. Psychol. Gen. 143, 804 (2014).

[104] L. S. Blackwell, K. H. Trzesniewski, and C. S. Dweck, Implicit theories of intelligence predict achievement across an adolescent transition: A longitudinal study and an intervention, Child Dev. 78, 246 (2007).

[105] F. Lawrenz, N. B. Wood, A. Kirchhoff, N. K. Kim, and A. Eisenkraft, Variables affecting physics achievement, J. Res. Sci. Teach. 46, 961 (2009). 